Prehospital care in Europe

\section{Pre hospital care in Europe}

\section{R Fairhurst}

The delivery of prehospital care varies greatly across Europe, but the Hesculaep Project funded by the European Union aims to map the provision of prehospital care in the 25 countries of Europe.

$\mathrm{T}$ he Hesculaep ${ }^{1}$ Project funded by the European Union aims to map the provision of prehospital care in the 25 countries of Europe. The end point will be a web enabled database. The project is led by the Assistance Publique Hôpitaux de Paris - SAMU 92. The project has four objectives:-

1. The exchange of information between national and regional organisations on the prehospital management of medical emergencies throughout the European Union.

2. The identification and analysis of national and regional research programmes in the management of medical emergencies.

3. Implementation of joint activities between the countries of the European Union.

4. Cross boundary programme of research in prehospital emergency medical care.

The delivery of prehospital care varies greatly between the 25 countries of Europe, and in some cases between different regions of the same country. ${ }^{2}$

In most countries, prehospital care is delivered by doctors, often as part of training in another speciality. However, in some of the new countries the mere possession of a medical qualification is considered sufficient.

Even in countries such as France and Germany, with apparently well developed EMS Systems, the delivery of care is not uniform. For example, in France, the SAMU (System d'aid Medical d' Urgence) does not cover the whole of the country. In many areas, services are provided by the Fire Services (Sappeurs Pompiers). The training of doctors is not standardised. Most are in a speciality training programme for emergency medicine. There is a reliance on general practitioners and indeed doctors from other specialties working in a part time and often ad hoc manner.

Paramedics defined as practitioners providing autonomous care are virtually unknown except in Scandinavia. In most of Europe command and control is exercised by doctors. They provide the hands-on triage of calls. Algorithmic systems such as American Medical Priority Despatch, which is widely used in the UK is only used in the most basic of formats.

The only country which prehospital care is recognised as a speciality is France, where it is included in the recently recognised Medicine $\mathrm{d}^{\prime}$ Urgence (Emergency Medicine). Indeed only in the UK, Ireland, and France is emergency medicine in hospital recognised as a speciality.
Even the emergency call telephone number varies. The number 112 should be available in all countries in Europe, it is not. France uses 15, Czechoslovakial55. The UK of course uses 999, though how many people know that if they dial 112 they will contact the emergency services?

Does this variation matter? Clearly it does for the citizens of Europe travelling away from their homes. It also makes it difficult to draw any meaningful international comparisons or indeed to benchmark. In England we should not be complacent. We have 31 ambulance services with different standard operating procedures and equipment. There are three ambulance triage systems and three telephone advice software systems. ${ }^{3}$ We have yet to decide if prehospital medicine should be a medical sub-speciality, and if so, of which speciality or specialities. Indeed we have not yet defined the scope of prehospital emergency medical practice.

We should not be complacent about the apparent chaos in Europe. We should concentrate on putting our own house in order. Much has been achieved but much remains to be done.

Emerg Med J 2005;22:760.

doi: $10.1136 / \mathrm{emj} .2005 .030601$

Correspondence to: Richard Fairhurst, NHS Lancashire Ambulance Service, 449-451

Garstang Road, Broughton, Preston PR3 5LN Richard.fairhurst@las-tr.nwest.nhs.uk

Accepted for publication 13 September 2005

\section{REFERENCES}

1 European Union: Sixth Framework Programme ERA-NET Scheme, 510232 12/09/ 2003.

2 States, Regions and EMS: Levels of decision, funding and evaluation. A report within the Hesculaep Project: Mija Edestrom, Caroline Weeks, Ulrika Winblad- Spangberg. University of Uppsala.

3 Taking Healthcare to the Patient, Transforming NHS Ambulance Services: Depatment of Health June 20053.10 